EPJ Web of Conferences 12, 02001 (2011)

DOI: $10.1051 /$ epjconf/20111202001

(C) Owned by the authors, published by EDP Sciences, 2011

\title{
Penetration of gas into concrete during a leakage rate test of reactor containments and its significance for the drop in pressure
}

\author{
L.-O. Nilsson ${ }^{\mathrm{a}}$ \\ Laboratory of Building Materials, University of Lund, PO Box 118, 22100 Lund, Sweden
}

\begin{abstract}
The objective of the project described in the paper was to develop a simulation model that describes transient air pressure distribution in concrete in order to see if the leakage rates obtained from the Containment Integrated Leakage Rate Tests can be explained by the transient air pressurization of concrete pores inside the steel liner. A partial differential equation was derived which describes transient air pressure distribution in concrete pores. The model was validated against experimental results. The simulation model shows that there are significant air fluxes into the concrete structures that can explain the pressure drop during a leakage test.
\end{abstract}

\section{INTRODUCTION}

Reactor containments in Sweden mainly consist of large cylinder shaped constructions made of reinforced concrete. There is also a lot of concrete inside the containments in the form of beams, walls and foundations. Inside the concrete cylinder shell a steel liner is embedded which acts as a leak-tight barrier.

The main objective of the project described in the paper was to develop a simulation model that describes transient air pressure distribution in concrete in order to see if the leakage rates obtained from the CILRT (Containment Integrated Leakage Rate Tests) [1] can be explained by the transient air pressurization of concrete pores inside the steel liner.

A partial differential equation was derived which describes transient air pressure distribution in concrete pores. The model was validated against experimental results using the computer software Comsol Multiphysics. A simplified finite differences model was also developed in Excel. The permeability and other material properties of relevant concretes were measured. A laboratory test setup was used for verification. At two occasions measurements were done during a pressure test at two PWRs. Moisture and pressure profiles were measured at various points in the concrete structures.

\section{LEAKAGE TESTS}

A reactor containment must be tested for leakage regularly; every third year in Sweden. The test is made by pumping up an air pressure, close the containment and measure the drop in pressure. The pressure drop is then translated into a leakage flow through the containment envelope.

The process is done in five steps that are shown in principle in figure 1 .

The steps are

1. "Pressurization" with a constant rate of increasing the pressure.

2. "Stabilisation" to let temperature variations equilibrate.

ae-mail: lars-olof.nilsson@byggtek.1th.se

This is an Open Access article distributed under the terms of the Creative Commons Attribution-Noncommercial License 3.0, which permits unrestricted use, distribution, and reproduction in any noncommercial medium, provided the original work is properly cited. 


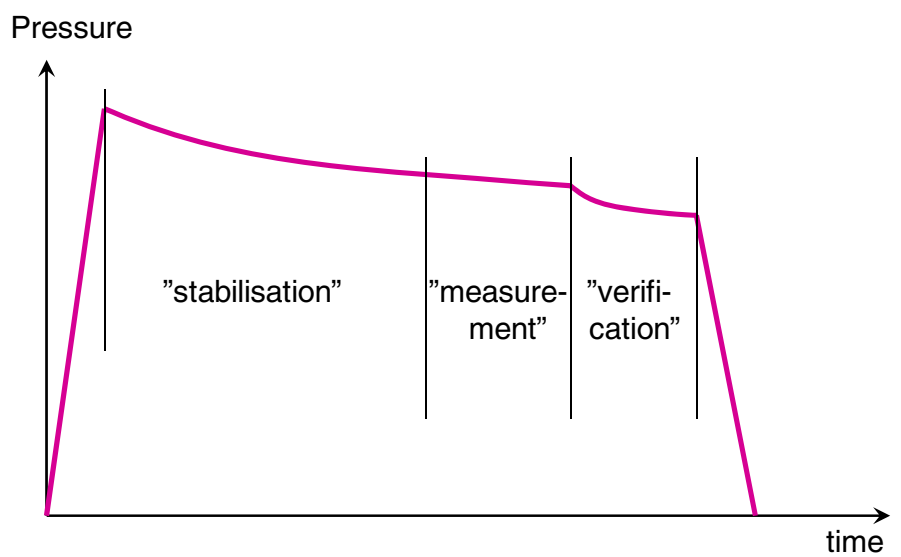

Figure 1. The pressure changes in the containment, in principle, during a leakage test.

3. "Measurement" during a certain time, normally eight hours.

4. "Verification" when a valve is opened to give an extra, known, gas flow out of the containment.

5. "Depressurization" with a constant rate of decreasing the pressure until atmospheric pressure is reached.

The hypothesis here is that the pressure drop is due to air penetrating into the concrete structures inside the steel liner in the containment envelope, without any leakage necessarily being a part of the process. To predict such a process the gas flow and the gas pressure changes at different depths and in the air volume must be quantified during all five steps. The differences between the five steps are the boundary conditions at the concrete surfaces:

1. The air pressure increases linearly with time, but some of the air is penetrating into concrete surfaces.

2. The air volume in the containment is kept constant; the air pressure drops due to gas flow into the concrete surfaces. The temperature drops and so does the air pressure.

3. The air volume is kept constant; the pressure drop is measured.

4. The mass of air is reduced with the constant air flow $\mathrm{Q}_{\text {out }}[\mathrm{kg} / \mathrm{s}]$ out of the containment.

5. The air pressure is lowered linearly with time, slowly to avoid damage of the painted surfaces.

\section{THEORETICAL MODELS}

\subsection{Air flow in concrete}

The air flow in a porous material is usually described as a volume flow [2], since that is what is measured. Such a description means that the gas volume must be corrected for the local gas pressure. To model the non-steady state gas penetration a mass balance equation for the mass of air must be solved. Because of that the air flow is here described by a mass flow. The required air permeability $K$ can of course be translated from measurements. The mass flow air may be written

$$
q=-\frac{K}{v} \cdot \frac{\partial P}{\partial x} \quad\left[\mathrm{~kg} /\left(\mathrm{m}^{2} \mathrm{~s}\right)\right]
$$

where $\mathrm{K}=$ permeability $\left(\mathrm{m}^{2}\right)$ and $v=$ kinematic viscosity $\left(\mathrm{m}^{2} / \mathrm{s}\right)$.

The kinematic viscosity can be described by

$$
v=\frac{\mu}{\rho}
$$




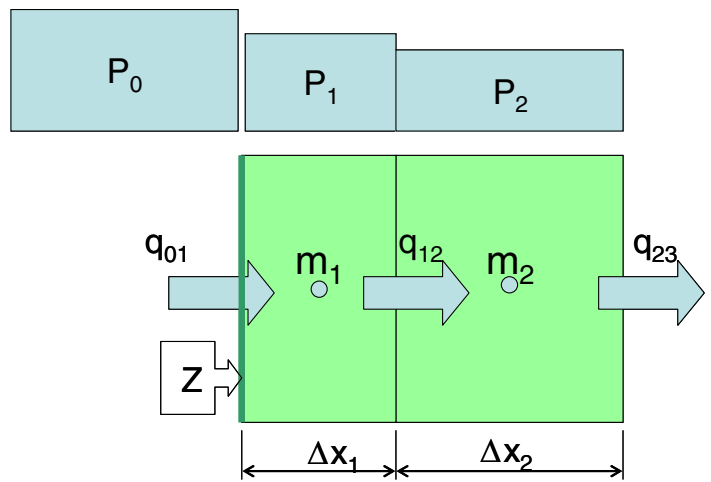

Figure 2. Mass balances of air in concrete for a numerical solution by finite differences.

where $\mu=$ dynamic viscosity $(\mathrm{kg} /(\mathrm{ms}))$ of air and $\rho=$ density of air $\left(\mathrm{kg} / \mathrm{m}^{3}\right)$. The dynamic viscosity is independent of pressure but somewhat temperature dependent. If the temperature is assumed to be constant, then the dynamic viscosity will be constant. law

The density of air depends of course on the air pressure. The density can be derived from the gas

$$
\rho=\frac{m}{V}=\frac{P \cdot M}{R T} .
$$

Consequently, the air flow can be calculated with

$$
q=-\frac{K}{\mu} \cdot \rho \cdot \frac{\partial P}{\partial x}=-\frac{K}{\mu} \cdot \frac{P \cdot M}{R T} \cdot \frac{\partial P}{\partial x}=-\frac{K}{\mu} \cdot \frac{M}{R T} \cdot P \cdot \frac{\partial P}{\partial x} .
$$

Here all parameters are constants except the permeability and the pressure. The permeability varies slightly with the pressure, but this is neglected in this first version of the model.

Where a surface cover is present, the permeability of the cover should be described by a resistance $\mathrm{Z}$ against air flow

$$
Z=\frac{\Delta x_{\text {surface }}}{K_{\text {surface }}} \quad[1 / \mathrm{m}]
$$

where $\Delta \mathrm{x}_{\text {surface }}$ is the thickness of the surface cover and $K_{\text {surface }}$ its permeability. The flow through the surface cover is then

$$
q=-\frac{1}{\mu} \cdot \frac{M}{R T} \cdot P \cdot \frac{\Delta P}{Z} .
$$

If a surface cover is combined with a thin slice of concrete with thickness $\Delta \mathrm{x}$ and permeability $K$ the flow can easily be described by adding the two resistances $Z+\Delta \mathrm{x} / \mathrm{K}$. The pressure in the flow equation can be chosen as the mean value of the pressures at the two sides of the combined materials.

\subsection{Mass balance in concrete}

Penetration of air and pressure changes with time can be calculated by solving the mass balance equation for each volume of concrete and calculate the air flow into the concrete surface from this solution.

The mass balance equation for air in concrete is given in figure 2 and equation (7).

The change with time of the mass $\mathrm{m}$ of air in the pore system of the concrete follows from the difference in flow to and from each point $x$ in the material. In equation (7) the mass balance equation is 


\section{EPJ Web of Conferences}

given as a partial differential equation and a finite difference equation

$$
\begin{aligned}
& \frac{\partial m}{\partial t}=-\frac{\partial q}{\partial x} \cdot V_{\text {concrete }} \\
& \text { or } \\
& \Delta m=\frac{\left(q_{1}-q_{2}\right)}{\Delta x} \cdot V_{\text {concrete }} \cdot \Delta t \quad[\mathrm{~kg}] .
\end{aligned}
$$

The top part of equation (7) is used in the 3D, FEM-model, and the bottom part is used in the 1D-model where it is solved by finite differences. These two different ways to describe the same processes are also used in the next equations.

\subsection{Pressure changes in concrete}

The change in pressure in the point at depth $\mathrm{x}$ is given by equation (8).

$$
\begin{aligned}
\frac{\partial P}{\partial t} & =\frac{\partial}{\partial t}\left(\frac{m}{M \cdot V_{\text {air }}} R T\right)=\frac{\partial m}{\partial t} \cdot \frac{R T}{M} \cdot \frac{1}{V_{\text {air }}} \\
\text { or } & \\
\Delta P & =\Delta m \cdot \frac{R T}{M} \cdot \frac{1}{V_{\text {air }}}=\frac{\left(q_{1}-q_{2}\right)}{\Delta x} \cdot \frac{R T}{M} \cdot \frac{1}{V_{\text {air }}} \cdot V_{\text {concrete }} \cdot \Delta t= \\
& =\frac{\left(q_{1}-q_{2}\right)}{\Delta x} \cdot \frac{R T}{M} \cdot \frac{1}{V_{\text {air }} / V_{\text {concrete }}} \cdot \Delta t \quad[P a] .
\end{aligned}
$$

Here $V_{\text {air }} / V_{\text {concrete }}$ is the porosity that is available to air, called $\pi_{a i r}$ by [3]. It is calculated from the porosity $\mathrm{p}$ and the degree of water saturation $\mathrm{S}$

$$
\pi_{l u f t}=p \cdot(1-S)
$$

The "available porosity" should also include the dissolution of air in the pore water, which is not insignificant [4]. This is, however, not included in this first version of the model.

\subsection{Mass balance in the air volume}

The mass balance in the air volume inside the containment, after the maximum pressure is reached after step 1 , is influenced by the inflow into all the concrete surfaces

$$
\begin{aligned}
& \Delta m_{\text {air volume }}(t)=-\int_{i} q_{i} \cdot A_{i} \cdot d t \\
& \text { or } \\
& \Delta m_{\text {air volume }}(t)=-\sum_{i=1}^{i=n} q_{i}(x=0, t) \cdot A_{i} \cdot \Delta t .
\end{aligned}
$$



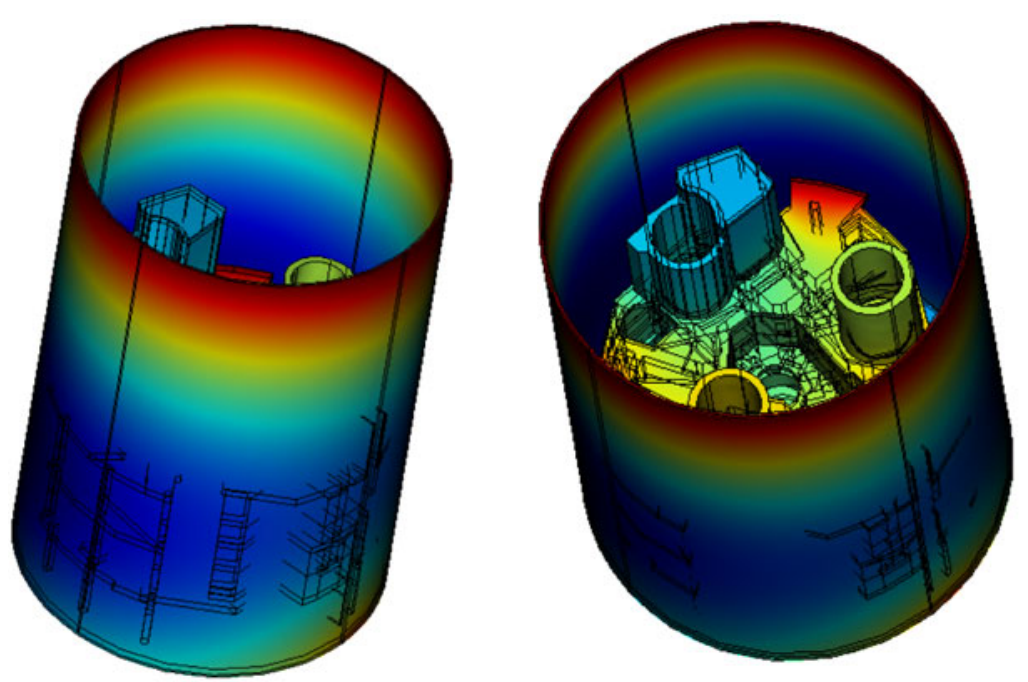

Figure 3. 3D-model of the concrete parts of the reactor containment.

Then the pressure drop is calculated from

$$
\begin{aligned}
& \frac{\partial P_{\text {air volume }}}{\partial t}=\frac{\partial m_{\text {air volume }}}{\partial t} \cdot \frac{R T}{M} \cdot \frac{1}{V_{\text {air volume }}} \\
& \text { or } \\
& \Delta P=\Delta m \cdot \frac{R T}{M} \cdot \frac{1}{V_{\text {air volume }}} \quad[P a] .
\end{aligned}
$$

\subsection{D-model}

With AutoCad a 3D-drawing was made of the concrete volumes inside the steel liner, from a drawing of a PWR-containment at Ringhals nuclear power station at the west coast of Sweden. This 3D-model was then imported into a FEM-tool, Comsol Multiphysics. The model is shown in figure 3.

The equations above were solved using the FEM-tool Comsol Multiphysics, for the geometry shown in figure 3. One example of a solution is shown in figure 4, as pressure distributions in the concrete volumes. In this example all concrete surfaces are assumed to be sealed by epoxy coatings, except the edges. The model also gives the pressure drop in the air volume inside the containment.

The 3D-model works well in Comsol Multiphysics. A series of calculations show that the pressure drop is strongly dependent on the permeability, and $\mathrm{RH}$, of the concrete and the portion of the concrete surfaces being open to air penetration. A large portion of the surfaces are coated with epoxy. These surfaces are, however, not completely sealed; minor cracks and other defects make air penetration possible. Because of this, it is very difficult to quantify the availability of surfaces that are open to air.

\subsection{Multiple 1D-model}

The Swedish nuclear power industry requested a more user-friendly tool to be able to verify the pressure drops during leakage tests in a simple way. Such a tool was developed in Microsoft Excel by using the same equations as above but describing the air flow in one dimension only. The concrete volumes inside the steel liner were modelled as a number of concrete volumes where air flow occurs in $1 \mathrm{D}$. The volumes 


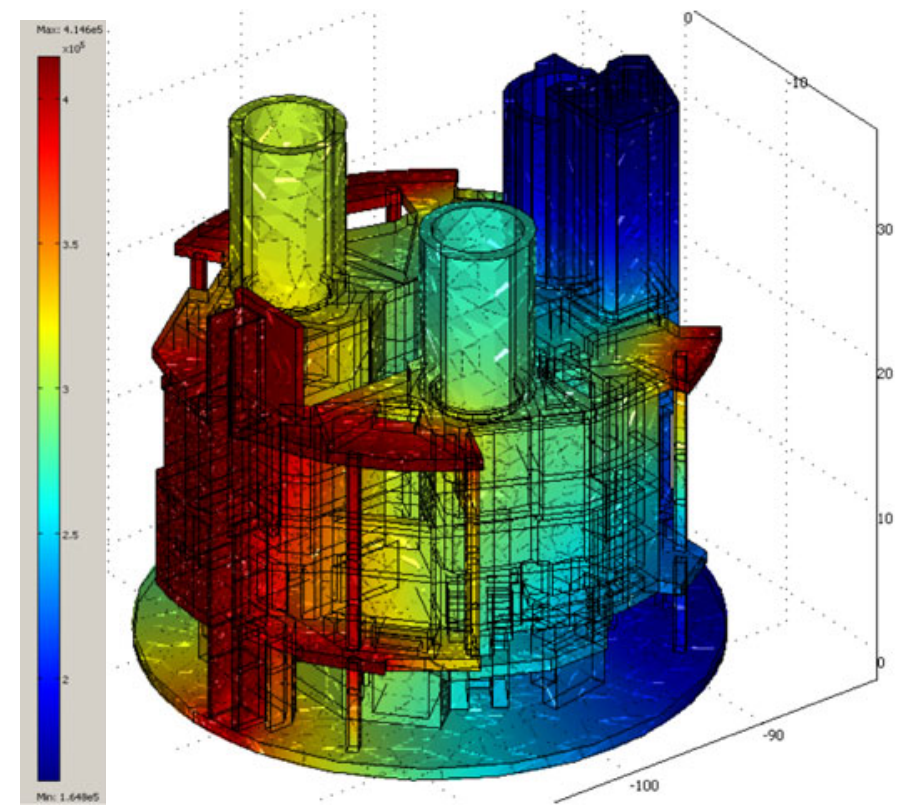

Figure 4. Example of pressure distribution in the internal concrete parts of the containment with all concrete surfaces, except the edges, sealed.

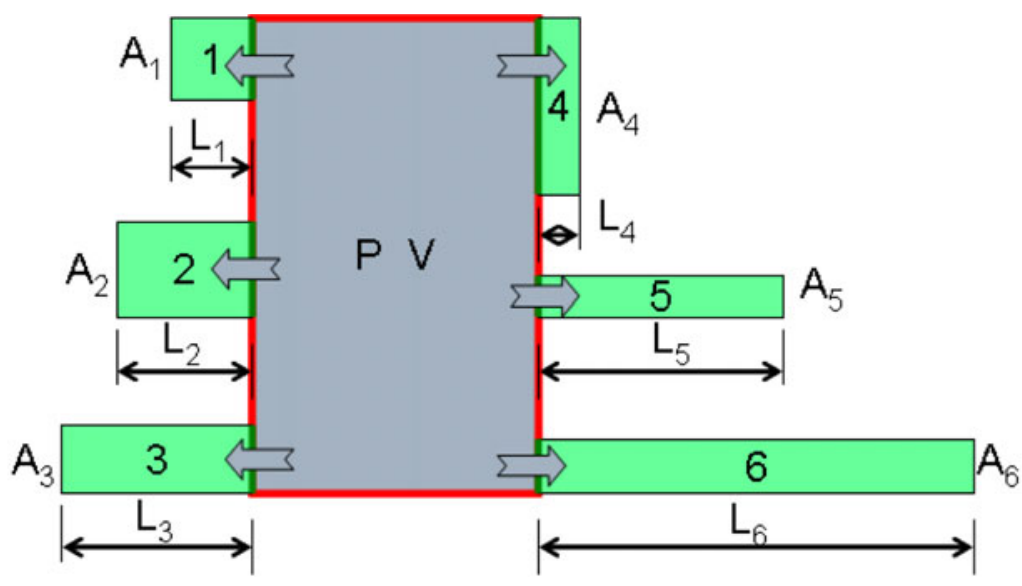

Figure 5. "Multiple" 1D-model with six concrete volumes (with thicknesses Li and surface areas Ai) connected to one air volume (with pressure $P$ and volume $V$ ).

have different areas $A_{i}$, thicknesses $L_{i}$ and surface cover. An example with six concrete volumes is shown in figure 5 , but a model with 30 volumes was also created.

The actual 3D-volume of all the concrete structures inside the steel liner must be divided into six (or 30) "representative" concrete volumes in such a way that these volumes together represent the total 3D-structure as good as possible with respect to the lengths of the air flow-path. Structural parts with approximately the same thickness are lumped together into one "concrete volume" with a certain thickness $L_{1}$. The total surface area of these structural parts, exposed to air, are added and called $A_{1}$. Other parts with a very different thickness are represented by another concrete volume with another 


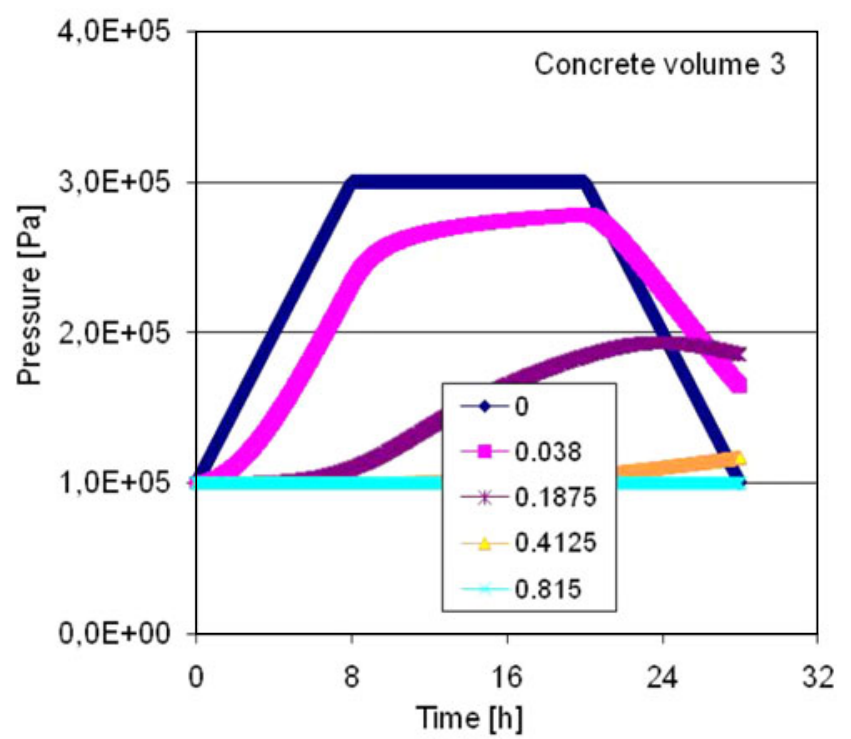

Figure 6. Example of pressure changes in a simulation with six concrete volumes; here No.3 with a thickness of $0.8 \mathrm{~m}$.

thickness $L_{i}$ and their total surface area is called $A_{i}$. In this way a series of concrete volumes with 1D air flow will represent all the 3D concrete structures.

The air volume inside the containment, around and in-between the structural parts, is modelled as one large volume of air, with a certain volume $V$ and one air pressure $P$, cf. figure 5 .

An example of calculation results from the six-volume model is shown in figure 6, as air pressure changes with time at different depths in one of the concrete volumes. One observation is that at large depths the air pressure continues to increase also after the start of the depressurization of the containment. This is also found in the field tests, see below.

\section{MATERIAL PROPERTIES}

The model requires a number of parameters to be quantified. The two most important ones are the air permeability $K$ and the porosity $\pi_{\text {air }}$ available to air. They are both functions of the moisture level in the pore system, cf. [5].

A limited amount of concrete specimens could be obtained from concrete cores drilled from a 30 year old reactor containment at Ringhals power station. The concrete had a water-cement ratio of 0.49 and a total porosity of $14 \%$. The specimens were conditioned to equilibrium with a series of RH, by drying at $+50^{\circ} \mathrm{C}$ in closed chambers above saturated salt solutions [6], to avoid surface cracking during drying.

The air permeability $K$ was measured with a Cembureau gas permeameter on four large concrete discs with a diameter of $150 \mathrm{~mm}$ and a thickness of $50 \mathrm{~mm}$. Four pressure levels were applied, up to a maximum pressure difference of $350 \mathrm{kPa}$. At each pressure level a steady state air flow was measured using a meniscus in a glass tube. The permeability was calculated as the mean value of the permeability at each pressure level. The variance was smaller than $6 \%$.

The available air porosity was determined on 50 small specimens by measuring the mass of the conditioned specimens before and after vacuum saturation under water. The results are shown in figure 7. 
EPJ Web of Conferences
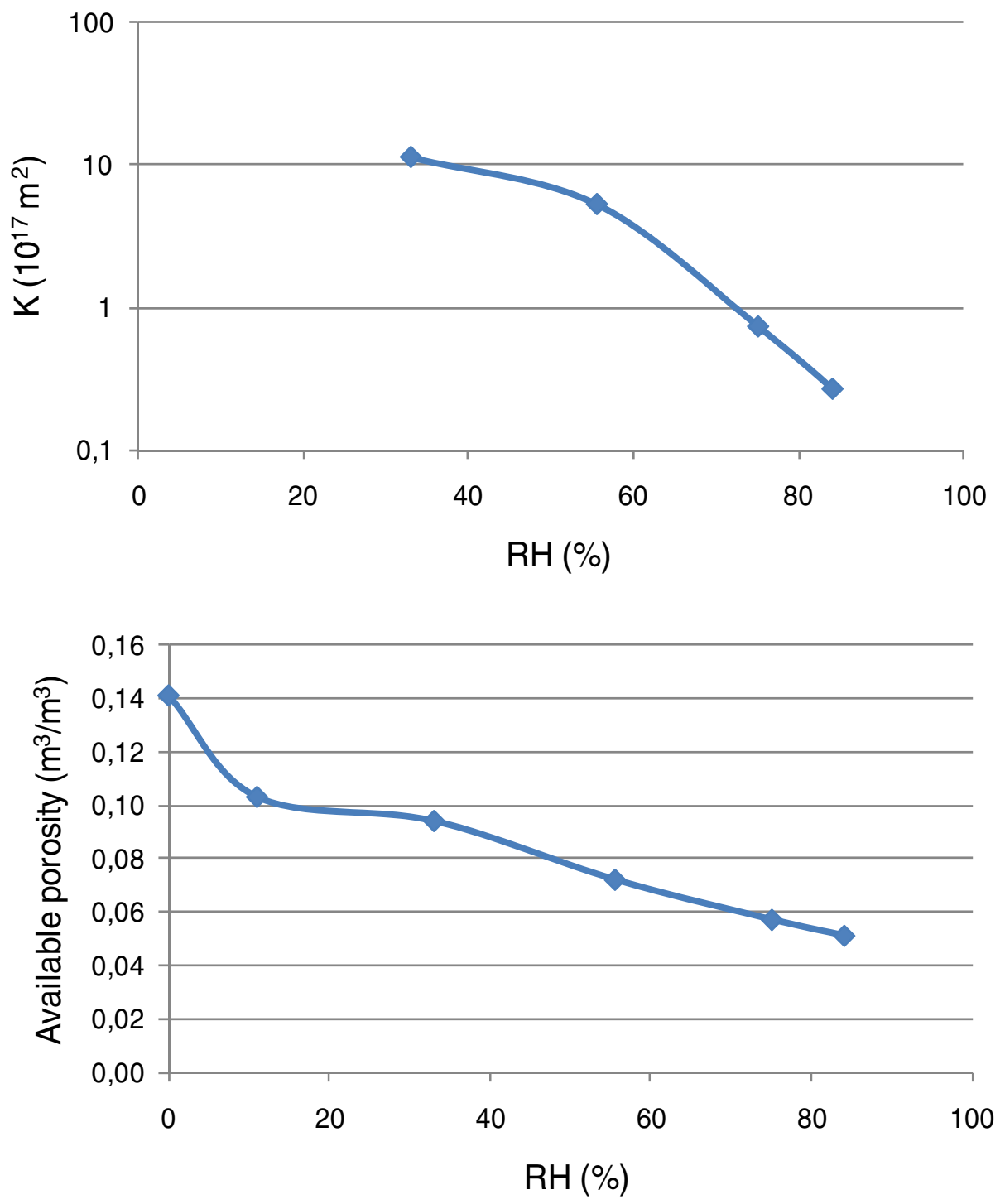

Figure 7. Gas permeability $K$ (top) and available porosity (bottom) as functions of concrete pore humidity RH measured on specimens taken from the Ringhals concrete containment.

\section{FIELD MEASUREMENTS}

Two attempts were made to measure pressure changes at different depths in the concrete volumes during leakage tests. In the final attempt 2008 that gave realistic results, the tubes with pressure transducers were placed in drilled holes that were injected with epoxy [5]. The RH-distribution was first measured in the same holes by inserting Vaisala RH-probes and wait for equilibrium for one day.

The results from three of the measuring points, in the thicker internal structures, are shown in figure 8 .

From figure 8 it is clear that there is a penetration of air into the concrete volumes. The pressures at a depth of $400 \mathrm{~mm}$ increases fairly rapid but at a depth of $800 \mathrm{~mm}$ the increase in pressure is much more retarded. Also after depressurization, at 38 hours after starting the measurements, the air pressure 
AMP 2010

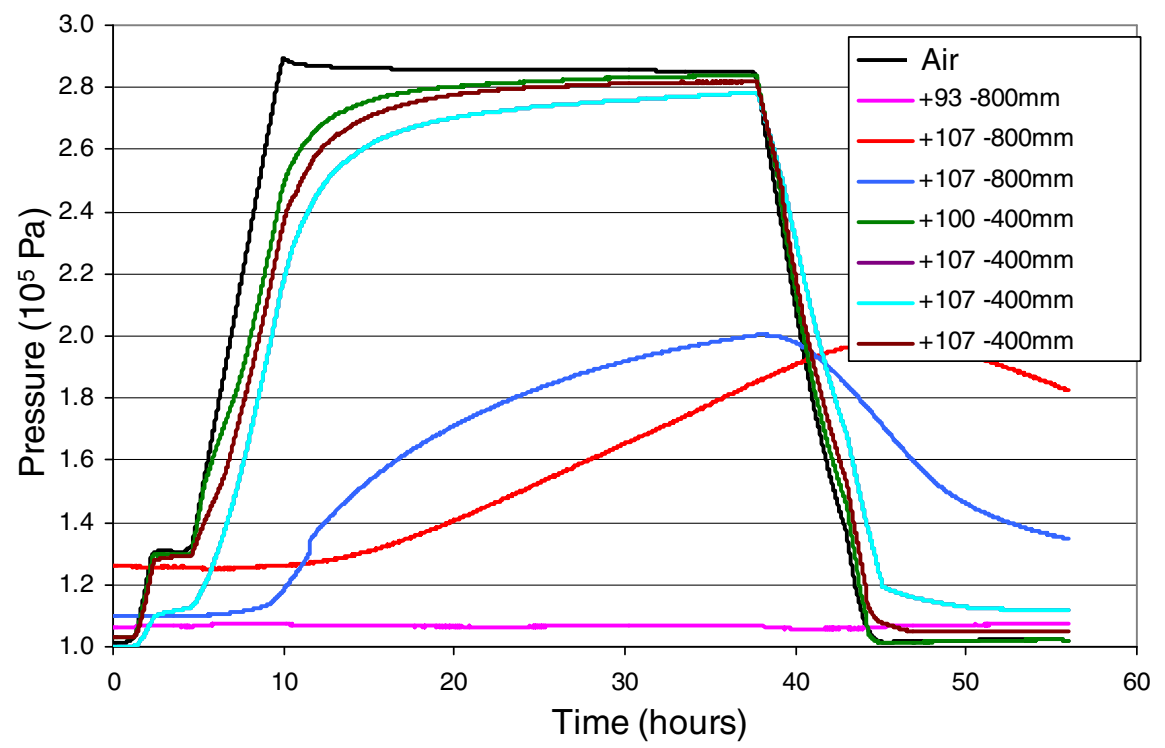

Figure 8. Pressure changes in the air and at different depths in the internal concrete structures in three measuring points during the leakage test at Ringhals R4 2008.

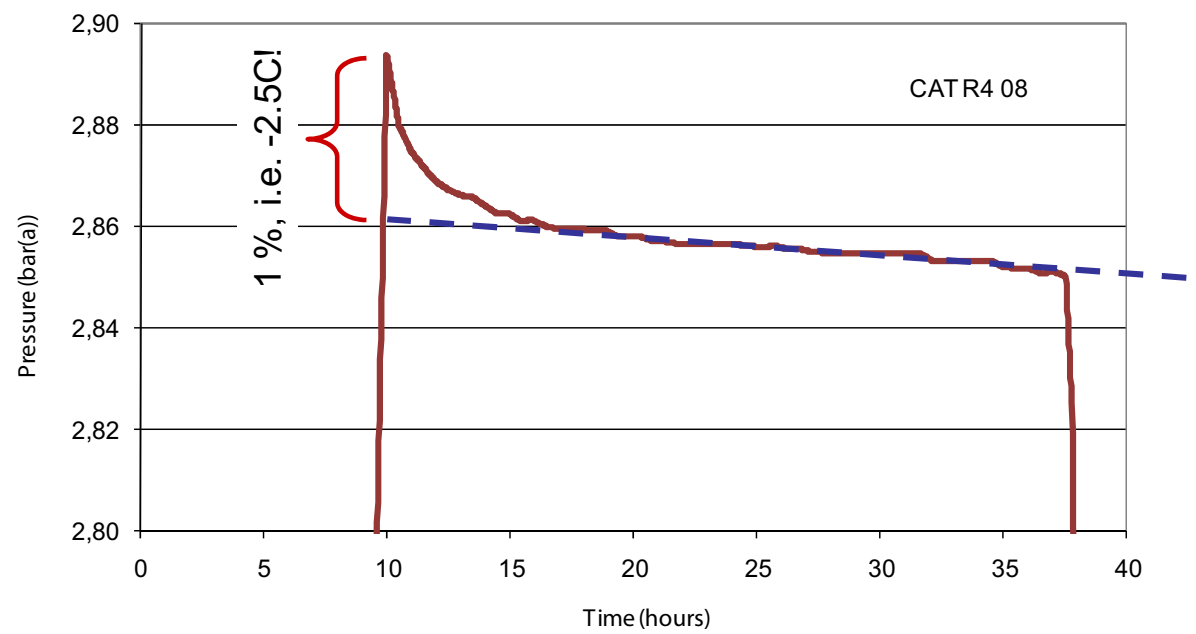

Figure 9. Pressure drop in the air volume of Ringhals R4 containment during the leakage test in 2008; a magnification of the top part of figure 8 .

continues to increase in one of the measuring points. This corresponds well with the calculation results from the model, cf. figure 6.

The drop in air pressure in the air volume inside the containment wall is shown in figure 9 . After the pressurization in step 1 there is a rapid drop in pressure during some 10 hours. This drop was shown to correspond to a drop in air temperature of some $2.5^{\circ} \mathrm{C}$. After that the pressure drop is almost linear with time and the rate of pressure drop corresponds with what can be achieved from the simulation model, depending on the assumptions made. 


\section{CONCLUSIONS}

The simulation model shows that, theoretically, there are significant air fluxes into the concrete structures and that the sum of these fluxes reduces the mass of air inside the containment during a pressure test. Consequently, this mass loss significantly reduces the air pressure during the test. These processes are strongly supported by the pressure measurements at different depths in the concrete. It is quite clear from the measurements that there is a tremendous rise in air pressure also at large depths, even after the pressure is lowered after the test. The measured drop in pressure does not necessarily indicate a leakage.

The simulation models are quite applicable but require detailed knowledge on the geometry and material properties of the concrete and the epoxy coatings at the concrete surfaces. The models could be improved also by including the effect of different moisture contents at different depths, the pressure dependency of the permeability and the dissolution of air into the moisture in the pore system.

The reported research was funded partly by Elforsk AB and partly by the Swedish Research Council Formas.

\section{References}

[1] ANSI/ANS-56.8-1994. American national standard for containment system leakage testing requirements. Illinois: American Nuclear Society.

[2] H.K. Hilsdorf, J. Kropp (eds.) Performance criteria for concrete durability. Cornwall: T.J. Press. (1995)

[3] P. Fredlund Gas transport in reactor containments of concrete (in Swedish). Master thesis, report TVBM-5069, Division of Building Materials, University of Lund (2006)

[4] G. Fagerlund The solubility of air in water. Private communication (2009)

[5] A. Abbas, M. Carcasses, J.-P. Ollivier Gas permeability of concrete in relation to its degree of saturation. Materials and Structures, Vol. 32. (1998)

[6] P. Fredlund, L.-O. Nilsson Gas penetration in reactor containments of concrete. Measurements and modeling (in Swedish). Report 09:101, Elforsk, Stockholm. www.elforsk.se (2009) 